\title{
Prevalence, risk factors and sources of anxiety among Emergency Department healthcare workers in Pakistan during COVID-19 pandemic: A single center survey
}

\author{
N. Haroon, S. S. Owais* (D), A. S. Khan and J. Amin \\ Emergency Department, Shifa International Hospital Ltd., Shifa Tameer-i-Millat University, H-8/4, Islamabad, Pakistan \\ *Corresponding author: E-mail: sobya.owais@gmail.com
}

(Received 07 September 2020; Revised 10 December 2020; Accepted 10 December 2020)

\begin{abstract}
Summary
COVID-19 has challenged the mental health of healthcare workers confronting it world-wide. Our study identifies the prevalence and risk of anxiety among emergency healthcare workers confronting COVID-19 in Pakistan. We conducted a cross-sectional survey in an Emergency Department using the Generalized Anxiety Scale (GAD-7), and questions about sources of anxiety. Of 107 participants, $61.7 \%$ were frontline workers. The prevalence of anxiety was $50.5 \%$. Nonparametric tests determined that nurses, younger and inexperienced staff, developed significant anxiety. Multivariate ordinal regression determined independent risk factors for developing anxiety were younger age (OR 2.11,95\% CI 0.89-4.99) and frontline placement (OR 1.34, 95\% CI 0.33-1.66). Significant sources of stress were fear of infecting family $(\mathrm{P}=0.003)$, lack of social support when the health care providers were themselves unwell $(\mathrm{P}=0.02)$ and feelings of inadequate work performance $(\mathrm{P}=0.05)$. Our study finds that $\mathrm{HCWs}$ ' anxiety is considerable. Appropriate measures for its alleviation and prevention are required.
\end{abstract}

Keywords: healthcare workers; anxiety; Pakistan; COVID-19 pandemic

\section{Introduction}

Since December 2019, the world is facing the novel coronavirus disease 2019 (COVID-19). The rapid disease transmission, increasing influx of infected persons and subsequent fatalities has led to tremendous panic. An early investigation into the psychological response among the general population of China showed that $53.8 \%$ of participants rated the psychological impact of this outbreak as moderate or severe (Elbay et al., 2020). The disease is highly infectious, primarily spreads through respiratory droplets and contact routes (World Health Organization, 2020), and can rapidly lead to deterioration in health. Empirical clinical data shows that the overall case fatality rate is $2.3 \%$ (Zhong et al., 2020).

COVID-19 has challenged all nations in several dimensions, among which is the mental health of medical staff (Spoorthy et al., 2020). Health care workers (HCWs) on the frontline are directly at risk of developing symptoms of psychological distress. The Centers for Disease Control and Prevention (CDC) warn HCWs about feelings of uncertainty, being overwhelmed, lacking motivation and having trouble sleeping or concentrating (Centers for Disease Control and Prevention, n.d.). The deluge of new cases, depletion of personal protection equipment, lack of definitive treatment, variable management guidelines, and inadequate social support, all contribute to the mental burden of HCWs. Fear of the contagion, infection of family and colleagues, and feelings of stigmatization lead to reluctance to

\footnotetext{
(c) The Author(s), 2020. Published by Cambridge University Press. This is an Open Access article, distributed under the terms of the Creative Commons Attribution licence (http://creativecommons.org/licenses/by/4.0), which permits unrestricted re-use, distribution and reproduction, provided the original article is properly cited.
} 
work and high levels of stress, anxiety, and depression, among some of the psychological implications (Lai et al., 2020).

\section{Objectives}

Pakistan has rarely addressed the mental health of its health care providers not withstanding this pandemic, with only one study on this subject (Sandesh et al., 2020). Since Pakistan's first case reported on 26 February, the total number of cases stands at 296,149 as of 31 August 2020 (Government of Pakistan, n.d.). This propagation in an already resource-poor country has placed tremendous physical and psychological pressure on its HCWs. Epidemiological data on the mental health consequences of COVID-19 and their screening, assessment, and management is lacking (Rana et al., 2020). This is especially true for frontline workers of the Emergency Department (ED), which is a high-risk area being the first stop for suspected COVID-19 patients. A study on Chinese ED HCWs showed prevalence rates of depressive symptoms and post-traumatic stress disorder at $25.2 \%$ and $9.1 \%$, respectively (Song et al., n.d.). We aim to identify the prevalence, risk factors and sources of anxiety among ED HCWs in Pakistan during the COVID-19 pandemic. The insight our study provides may entice further research into the diagnosis, treatment and prevention of the psychological impact of this crisis on this vulnerable group.

\section{Methods}

This cross-sectional survey was conducted from 1 May 2020 to 20 May 2020 in the ED of Shifa International Hospital (SIH), Islamabad, Pakistan. Ours is a small ED which sees around 40,000 patients per annum. Purposive total population sampling was chosen for the entire census of HCWs $(n=109)$ providing patient care during the defined time frame. ED surveys have been conducted on a similar sample frame (Abraham et al., 2018; Basu et al., 2016). Paper-based self-reporting questionnaires were distributed at the start of each work shift till all elements of the sample frame were included. The Institutional Review Board and Ethics Committee (IRB\&EC) provided ethical approval for the study. All subjects were invited to participate on a voluntary basis and they provided informed consent prior to study commencement.

\subsection{Materials}

Our questionnaire consisted of 25 questions divided in three sections. The first section queried about demographic and occupational characteristics. The next section of questions answered as "yes" or "no", pertained to specific sources of stress for HCWs while caring for COVID-19 patients: availability of personal protective equipment, their own physical and mental health, safety of their families, lack of social support and childcare, and feelings of incompetence and stress affecting work performance. These questions were derived from the prevailing concerns for HCWs (Shanafelt et al., 2020). Cai et al. used similar questions (Cai et al., 2020). The third section measured the anxiety symptoms among HCWs during the pandemic using the Generalized Anxiety Scale-7 (GAD-7) (Spitzer et al., 2006). GAD-7 is a validated, seven-item, self-reporting, screening questionnaire that assesses participants' mental health status during the previous 2 weeks (Williams, 2014). Each item is scored from 0 to 3 based on severity of symptoms experienced. The scores are then totaled from 0 to 21 with 5, 10 and 15 as cut-off points for mild, moderate and severe anxiety symptoms, respectively (Williams, 2014). GAD-7 has been widely used during the SARS-CoV-2 pandemic to evaluate the prevalence of anxiety symptoms among HCWs across the globe (Centers for Disease Control and Prevention, n.d.; Gupta et al., 2020; Wilson et al., 2020).

\subsection{Statistical analyses}

All study variables were coded numerically, including the degree of anxiety. The following analyses were carried out using SPSS 26.0 (IBM Corp): descriptive analyses, summarized as frequency (percentage); 
Table 1. Demographic and occupational characteristics of participants

\begin{tabular}{|c|c|c|c|c|}
\hline & Physician & Nurse & Paramedic & P-value \\
\hline Characteristic & No. (\%) & No. (\%) & No. $(\%)$ & \\
\hline Total & $50(46.7)$ & $50(46.7)$ & $7(6.5)$ & \\
\hline \multicolumn{5}{|l|}{ Age, No. (\%) } \\
\hline $21-30$ years & $31(41.9)$ & $38(51.4)$ & $5(6.7)$ & \\
\hline $31-40$ years & $14(50.0)$ & $12(42.9)$ & $2(7.1)$ & 0.361 \\
\hline $41-50$ years & $3(75.0)$ & $1(25.0)$ & 0 & \\
\hline $51-60$ years & $2(100.0)$ & 0 & 0 & \\
\hline \multicolumn{5}{|c|}{ Gender, No. (\%) } \\
\hline Male & $25(36.8)$ & $36(52.9)$ & $7(10.3)$ & 0.009 \\
\hline Female & $25(64.1)$ & $14(35.9)$ & 0 & \\
\hline \multicolumn{5}{|c|}{ Marital status, No. (\%) } \\
\hline Married & $24(42.9)$ & $28(50.0)$ & $4(7.1)$ & 0.052 \\
\hline Unmarried & $25(39.0)$ & $36(56.3)$ & $3(4.7)$ & \\
\hline \multicolumn{5}{|c|}{ Years of experience, No. (\%) } \\
\hline$\leq 2$ years & $24(42.9)$ & $28(50.0)$ & $4(7.1)$ & \\
\hline $3-5$ years & $17(53.1)$ & $14(43.8)$ & $1(3.1)$ & 0.772 \\
\hline $6-10$ years & $9(47.4)$ & $8(42.1)$ & $2(10.5)$ & \\
\hline \multicolumn{5}{|c|}{ Work placement, No. (\%) } \\
\hline Front-line & $24(35.3)$ & $37(54.4)$ & $7(10.3)$ & 0.024 \\
\hline Second-line & $26(66.6)$ & $13(33.3)$ & 0 & \\
\hline
\end{tabular}

nonparametric tests to identify the differences in categorical variables between groups, as the data did not conform to normality; multivariate ordinal regression to identify the association between demographic and occupational variables as independent risk factors for the development of anxiety according to severity presented as odds ratios (ORs) and 95\% CIs, after adjustment for confounders, including age, gender, marital status, designation, years of experience and work placement. P-value $\leq 0.05$ was statistically significant.

\section{Results}

A total of 109 questionnaires were collected, of which 107 were valid. Two responses were excluded because of incomplete data. The response rate was $98 \%$.

The demographic and occupational characteristics of all the participants are presented (Table 1). Male: female ratio of nurses and paramedical staff was greater as compared to almost equal numbers among physicians; more nurses and paramedical staff had worked as front-liners. These differences were statistically significant (Table 1).

\subsection{Comparison of severity of anxiety between groups}

The severity of anxiety was compared across all groups (Table 2). Half the participants experienced anxiety, most had mild symptoms. Six (5.6\%) healthcare workers reported severe anxiety, average GAD-7 
Table 2. Severity categories of anxiety in total cohort and subgroups

\begin{tabular}{|c|c|c|c|c|}
\hline \multirow{2}{*}{$\begin{array}{l}\text { Demographic, Occupational } \\
\text { Risk Factors }\end{array}$} & \multicolumn{4}{|c|}{ Severity of Anxiety } \\
\hline & Mild & Moderate & Severe & P-value \\
\hline Total, No. (\%) & $33(30.8)$ & $15(14.0)$ & $6(5.6)$ & \\
\hline \multicolumn{5}{|l|}{ Age (\%) } \\
\hline 21-30 years & $25(33.8)$ & $13(17.6)$ & $5(6.8)$ & \\
\hline $31-40$ years & $8(29.6)$ & $2(7.4)$ & $1(3.7)$ & 0.001 \\
\hline $41-50$ years & 0 & 0 & 0 & \\
\hline $51-60$ years & 0 & 0 & 0 & \\
\hline \multicolumn{5}{|l|}{ Gender (\%) } \\
\hline Male & $18(29.5)$ & $11(18.0)$ & $3(4.9)$ & \\
\hline Female & $15(32.6)$ & $4(8.4)$ & $3(6.5)$ & 0.5 \\
\hline \multicolumn{5}{|l|}{ Marital status (\%) } \\
\hline Married & $19(29.7)$ & $11(17.2)$ & $5(7.8)$ & \\
\hline Unmarried & $14(32.6)$ & $4(9.3)$ & $1(2.3)$ & 0.14 \\
\hline \multicolumn{5}{|l|}{ Designation (\%) } \\
\hline Physician & $13(26.0)$ & $4(8.0)$ & 0 & \\
\hline Nurse & $19(38.0)$ & $9(18.0)$ & $6(12.0)$ & 0.001 \\
\hline Paramedic & $1(14.3)$ & $2(28.6)$ & 0 & \\
\hline \multicolumn{5}{|l|}{ Years of experience (\%) } \\
\hline$\leq 2$ years & 19 (33.9) & $8(14.3)$ & $4(7.1)$ & \\
\hline $3-5$ years & $11(34.4)$ & $4(12.5)$ & $1(3.1)$ & 0.5 \\
\hline $6-10$ years & $3(15.8)$ & $3(15.8)$ & $1(5.3)$ & \\
\hline \multicolumn{5}{|l|}{ Work placement } \\
\hline Front-line & $21(31.8)$ & $13(19.7)$ & $6(9.1)$ & \\
\hline Second-line & $12(29.3)$ & $2(4.9)$ & 0 & 0.001 \\
\hline
\end{tabular}

score of $16.50( \pm 0.50)$; all were nurses and frontline workers. Nurses' mean score was $10.28( \pm 4.39)$, classified as moderate anxiety symptoms, whereas physicians' average score was $9.18( \pm 4.90)$, classified as mild symptoms. This difference was statistically significant $(\mathrm{P}=0.001)$. The younger age group $21-30$ years scored an average of 10.03 ( \pm 4.40$)$, compared to 31-40 years and 41-50 years mean scores of 9.55 $( \pm 5.10)$ and $5.75( \pm 5.50)$ respectively; the difference was statistically significant $(\mathrm{P}=0.035)$. Frontline workers' mean score was $9.80( \pm 4.50)$ compared to second-line workers' score of $9.30( \pm 4.90)$, which was statistically significant $(\mathrm{P}=0.001)$. The variables of gender, marital status and years of experience, were not significant when compared with the severity of anxiety.

\subsection{Risk factors for the development of anxiety}

The association between the demographic and occupational characteristics of participants and the development of anxiety symptoms showed the youngest age group (21-30 years) and frontline workers were at greatest risk of having anxiety $(\mathrm{P}=0.001$, OR $2.11,95 \% \mathrm{CI} 0.89-4.99$ and $\mathrm{P}=0.028, \mathrm{OR} 1.34$, $95 \%$ CI $0.33-1.66$, respectively). There was no association demonstrated between anxiety symptoms 
Table 3. Analysis of demographic and occupational factors associated with developing anxiety

\begin{tabular}{|c|c|c|c|}
\hline Demographic/occupational Risk Factors & No. of anxious/ Total number (\%) & Adjusted OR (95\% Cl) & P-value \\
\hline \multicolumn{4}{|l|}{ Age } \\
\hline $21-30$ years & $43 / 74(58.1)$ & $2.11(0.89-4.99)$ & \\
\hline $31-40$ years & $11 / 27(40.7)$ & $1.34(0.33-1.66)$ & 0.001 \\
\hline \multicolumn{4}{|l|}{ Gender } \\
\hline Male & $32 / 61(52.5)$ & $0.70(0.30-1.66)$ & \\
\hline Female & $22 / 46(47.8)$ & 1.0 & 0.42 \\
\hline \multicolumn{4}{|l|}{ Marital status } \\
\hline Unmarried & $19 / 43(44.2)$ & $0.83(0.32-2.21)$ & \\
\hline Married & $35 / 64(54.7)$ & 1.0 & 0.72 \\
\hline \multicolumn{4}{|l|}{ Designation } \\
\hline Physicians & $17 / 50(34.0)$ & $0.68(0.15-3.15)$ & \\
\hline Nurses & $34 / 50(68.0)$ & $0.63(0.15-2.71)$ & 0.58 \\
\hline Paramedics & $3 / 7(42.8)$ & 1.0 & \\
\hline \multicolumn{4}{|l|}{ Years of experience } \\
\hline$\leq 2$ years & $31 / 56(55.3)$ & $2.10(0.41-10.8)$ & \\
\hline 3-5years & $16 / 32(50.0)$ & $0.63(0.12-3.44)$ & 0.48 \\
\hline $6-10$ years & $7 / 19(36.8)$ & 1.0 & \\
\hline \multicolumn{4}{|l|}{ Work placement } \\
\hline Front-line & $40 / 66(60.2)$ & $0.37(0.15-0.90)$ & 0.028 \\
\hline Second-line & $14 / 41(34.1)$ & 1.0 & \\
\hline
\end{tabular}

and the other study variables including gender, marital status, designation and years of experience. (Table 3).

\subsection{Sources of stress}

Significant sources of stress among HCWs were the fear of carrying the infection home $(\mathrm{P}=0.003)$, lack of social support when the HCW were themselves unwell $(\mathrm{P}=0.02)$ and feelings of inadequate performance at work $(\mathrm{P}=0.05)$ (Table 4$)$.

\section{Discussion}

Anxiety is a natural response to stress. Stress is a normal body reaction to any changes that occur. The SARS-CoV-2 pandemic has abruptly and drastically changed the lives of people of all nations across the world. While HCWs of all types are caring for large surges of COVID-19 patients, it is essential to maintain their numbers while maximizing their abilities to perform to their full potential (Shanafelt et al., 2020). To this end, our study attempted to evaluate the prevalence, severity, sources and risk factors of anxiety symptoms that endanger the psychological health of HCWs. This was meant as a screening to identify requirements for professional referral and subsequent intervention. Studies on the mental health of HCWs in previous disease pandemics are well-document, yet there are marked differences compared with the current situation (Xiao et al., 2020). The subject of the ongoing 
Table 4. Sources of stress perceived by HCWs during the pandemic

\begin{tabular}{|c|c|c|c|c|}
\hline & Physicians & Nurses & Paramedics & \\
\hline Source of stress & $\mathrm{N}(\%)$ & $\mathrm{N}(\%)$ & $\mathrm{N}(\%)$ & P-value \\
\hline Lack of access to PPE & $28(45.2)$ & $32(51.6)$ & $2(3.2)$ & 0.19 \\
\hline Fear that PPE will run out & $38(52.8)$ & $29(40.3)$ & $5(6.9)$ & 0.15 \\
\hline Fear of infection at work & $40(48.8)$ & $37(45.1)$ & $5(6.1)$ & 0.73 \\
\hline Fear of infecting family & $47(48.5)$ & $44(45.4)$ & $6(6.2)$ & 0.003 \\
\hline Fear of death due to infection & $16(51.6)$ & $15(48.4)$ & 0 & 0.21 \\
\hline Lack of access to testing & $12(34.3)$ & $21(60.0)$ & $2(5.7)$ & 0.15 \\
\hline Lack of social support if one is sick & $25(37.3)$ & $38(56.7)$ & $4(6.0)$ & 0.02 \\
\hline Lack of childcare during lockdown & $16(43.2)$ & $19(51.4)$ & $2(5.4)$ & 0.77 \\
\hline Lack of competence for "Red Zone" work & $43(45.3)$ & $45(47.4)$ & $7(7.4)$ & 0.51 \\
\hline Lack of communication from hospital admin & $16(36.4)$ & $23(52.3)$ & $5(11.4)$ & 0.88 \\
\hline Feelings of inability to perform one's duty & $6(30.0)$ & $14(70.0)$ & 0 & 0.05 \\
\hline
\end{tabular}

psychological impact on HCWs during the COVID-19 pandemic has gained interest in many hard hit countries such as the U.S., China, Iran, India and Italy (Centers for Disease Control and Prevention, $\mathrm{n}$. d.; Gupta et al., 2020; Kaveh et al., 2020; Pearman et al., 2020; Rossi et al., 2020; Song et al., n.d.; Wilson et al., 2020; Xiao et al., 2020).

We chose the ED as the setting for our study. EDs across the globe have borne the brunt of managing COVID-19 patients; however the psychological impact on this particular subgroup of HCWs has yet to be studied. We included all elements directly involved in patient care, including paramedical staffs who are technical assistants to aide physicians and nurses with surgical procedures in the ED. An enormous challenge in this crisis has been the restructure of the work flow of hospitals to accommodate the influx of patients while containing the cross-transmission of disease. In our ED, a separate negative pressure isolation area has been dedicated for suspected/confirmed COVID-19 cases, named the "Red Zone", where staff was randomly rotated at regular intervals. Those who had worked in the "Red Zone" were considered as front-line workers, while those who had not were considered as second-line. Most of our participants had worked in the "Red Zone".

Nearly half of our participants reported symptoms of anxiety, but mild symptoms accounted for a larger proportion of disturbances; only 5.6\% reported severe symptoms. Among Chinese HCWs, anxiety symptoms ranged from 11.4-50\% (Centers for Disease Control and Prevention, n.d.; Song et al., n.d.; Zhu et al., 2020). Similar to our observation, studies from Iran and India demonstrated that the majority of HCWs had minimal to mild anxiety symptoms (Kaveh et al., 2020; Wilson et al., 2020). Younger age and working at the frontline were found to be independent risk factors for developing severe anxiety symptoms. Lai et al. from China also observed the latter (Lai et al., 2020). Other countries have seen higher anxiety levels in younger HCWs ( $<40$ years of age), who were more likely to be female, which was not observed in our participants (Badahdah et al., 2020; Kaveh et al., 2020). We also identified significant sources of distress according to occupational designation. Our results are similar to those of a meta-analysis exploring the factors related to HCWs' psychological difficulties, which found that infection of colleagues or family members, protective measures, and medical violence were among the main concerns of HCWs in COVID-19 affected areas (Pappa et al., n.d.). Similar results were observed by Cai et al. (2020). Surprisingly, lack of personal protective equipment was not a significant source of anxiety in our cohort. This may arise as a concern in other settings or a different time frame. 
COVID-19 has adversely affected healthcare systems, created public health challenges and unnerved health service providers world-wide. Recognizing the most vulnerable HCWs, working in high-risk areas such as the ED, it is essential to provide them with support for coping with the emerging situation. Our hospital designed mental health facilities for HCWs specific to this crisis in the form of informative webinars and group sessions, as well mandatory screening sessions by professionals. Those suffering from severe symptoms were offered one-on-one sessions while maintaining their confidentiality. Timely assessment and provision of appropriate resources by the relevant healthcare authorities to combat, as well as prevent these disturbances is greatly needed, especially as the end of the pandemic is as yet, out of sight.

Our study has several limitations. Our scope was limited to screening for anxiety symptoms and identifying stressors. The actual prevalence of clinically diagnosed anxiety may vary. Stressors will vary individually and according to the prevailing situation, not all can be covered. The results of our study cannot be generalized to all HCWs working in EDs locally or internationally unless similar studies are undertaken in their settings on a larger sample of randomized subjects. Although our response rate was high and we used a validated screening tool, response bias is a possibility. Since it was a cross-sectional observation, longitudinal follow-up is lacking. This is required to assess the long-term effects of such crises on HCWs, providing future avenues of research. Furthermore, the mental health condition of HCWs themselves infected with COVID-19 is also a subject to be explored.

\section{Conclusion}

Our study aimed to identify the presence of anxiety symptoms and sources of distress among HCWs of an ED in Pakistan during the SARS-CoV-2 pandemic. We found the degree of anxiety symptoms to be mild; young nursing staff who had direct contact with infected patients were more affected. Significant sources of stress included fear of infecting family, lack of social support when the HCW were themselves unwell and feelings of inadequate work performance. Provision of appropriate measures to alleviate as well as prevent anxiety in HCWs is the need of the hour.

Acknowledgment. The authors sincerely appreciate the participation in this study of all the medical staff who are fighting against COVID-19.

Financial support. None to declare.

Conflict of interest. None to declare.

Data availability statement. The data that support the findings of this study are openly available in Pubmed Central at. http:// https://www.ncbi.nlm.nih.gov/pmc/, reference numbers 1, 3-7, 9-25;

World Health Organization at https://apps.who.int/iris/bitstream/handle/10665/331616/WHO-2019-nCoV-Sci_Brief-Trans mission_modes-2020.2-eng.pdf, reference number 2;

The official website of the Government of Pakistan at http://covid.gov.pk/stats/pakistan, reference number 7.

Author contributions.

a. N. Haroon: concept and design, drafting of manuscript.

b. S. S. Owais: data acquisition, analysis, interpretation, takes responsibility for data integrity and accuracy; drafting of manuscript

c. A. S. Khan: critical appraisal; administrative support

d. J. Amin: data acquisition, technical support

Disclaimer. This is an original work. All references have been clearly cited. This manuscript has not been published, nor is it under consideration for publication elsewhere.

\section{References}

Abraham, L. J., Thom, O., Greenslade, J. H., Wallis, M., Johnston, A. N., Carlström, E., Mills, D., \& Crilly, J. (2018). Morale, stress and coping strategies of staff working in the Emergency Department: A comparison of two different-sized departments. Emergency Medicine Australasia, 30, 375-381. doi: https://doi.org/10.1111/1742-6723.12895. 
Badahdah, A. M., Khamis, F., \& Mahyijari, N. A. (2020). The psychological well-being of physicians during COVID-19 outbreak in Oman. Psychiatry Research, 289, 113053.

Basu, S., Yap, C., \& Mason, S. (2016). Examining the sources of occupational stress in an Emergency Department. Occupational Medicine (London), 66, 737-742.

Cai, H., Tu, B., Ma, J., Chen, L., Fu, L., Jiang, Y., \& Zhuang, Q. (2020). Psychological impact and coping strategies of frontline medical staff in Hunan between January and March 2020 during the outbreak of Coronavirus disease 2019 (COVID-19) in Hubei, China. Medical Science Monitor, 26, e924171. doi: https://doi.org/10.12659/MSM.924171.

Centers for Disease Control and Prevention. (n.d.). Healthcare workers and first responders: How to cope with stress and build resilience during the COVID-19 pandemic. https://www.cdc.gov/coronavirus/2019-ncov/hcp/mental-health-healthcare.html

Elbay, R. Y., Kurtulmuş, A., Arpacioğlu, S., \& Karadere, E. (2020). Depression, anxiety, stress levels of physicians and associated factors in Covid-19 pandemic. Psychiatry Research, 290, 113130. doi: https://doi.org/10.1016\%2Fj.psychres.2020.113130.

COVID-19 Health Advisory Platform by Ministry of National Health Services Regulation and Coordination. http://covid.gov. $\mathrm{pk} /$ stats/pakistan. Accessed 1 Sept 2020.

Gupta, A. K., Mehra, A., Niraula, A., Kafle, K., Deo, S. P., Singh, B., Sahoo, S., \& Grover, S. (2020). Prevalence of anxiety and depression among the healthcare workers in Nepal during the COVID-19 pandemic. Asian Journal of Psychiatry, 54, 102260. doi: https://doi.org/10.1016/j.ajp.2020.102260.

Kaveh, M., Davari-tanha, F., Varaei, S., Shirali, E., Shokouhi, N., Nazemi, P., Ghajarzadeh, M., Feizabad, E., \& Ashraf, M. A. (2020). Anxiety levels among Iranian health care workers during the COVID-19 surge: A cross-sectional study. MedRxiv Published online: 6 May 2020. https://doi.org/10.1101/2020.05.02.20089045

Lai, J., Ma, S., Wang, Y., Cai, Z., Hu, J., Wei, N., Wu, J., Du, H., Chen, T., Li, R., Tan, H., Kang, L., Yao, L., Huang, M., Wang, H., Wang, G., Liu, Z., \& Hu, S. (2020). Factors associated with mental health outcomes among healthcare workers exposed to Coronavirus disease 2019. JAMA Network Open, 3, e203976.

Pappa, S., Ntella, V., Giannakas, T., Giannakoulis, V. G., Papoutsi, E., \& Katsaounou, P. (n.d.). Prevalence of depression, anxiety, and insomnia among healthcare workers during the COVID-19 pandemic: A systematic review and meta-analysis. Brain, Behavior, and Immunity, 88, 901-907. s0889-1591(20)30845-X. https://doi.org/10.1016/j.bbi.2020.05.026

Pearman, A., Hughes, M. L., Smith, E. L., \& Neupert, S. D. (2020). Mental health challenges of U.S. healthcare professionals during COVID-19. Frontiers in Psychology, 11, 2065. doi: https://www.frontiersin.org/articles/10.3389/fpsyg.2020.02065/ abstract.

Rana, W., Mukhtar, S., \& Mukhtar, S. (2020). Mental health of medical workers in Pakistan during the pandemic COVID-19 outbreak. Asian Journal of Psychiatry, 51, 102080

Rossi, R., Socci, V., Pacitti, F., Di Lorenzo, G., Di Marco, A., Siracusano, A., \& Rossi, A. (2020). Mental health outcomes among frontline and second-Line health care workers during the Coronavirus Disease 2019 (COVID-19) pandemic in Italy. JAMA Network Open, 3, e2010185. doi: https://doi.org/10.1001/jamanetworkopen.2020.10185.

Sandesh, R., Shahid, W., Dev, K., Mandhan, N., Shankar, P., Shaikh, A., \& Rizwan, A. (2020). Impact of COVID-19 on the Mental Health of Healthcare Professionals in Pakistan. Cureus, 12, e8974. doi: https://doi.org/10.7759/cureus.8974.

Shanafelt, T., Ripp, J., \& Trockel, M. (2020). Understanding and addressing sources of anxiety among health care professionals during the COVID-19 pandemic. JAMA, 323, 2133-2134. doi: https://doi.org/10.1001/jama.2020.5893.

Song, X., Fu, W., Liu, X., Luo, Z., Wang, R., Zhoug, N., Yan, S., \& Lv, C. (n.d.). Mental health status of medical staff in Emergency Departments during the Coronavirus disease 2019 epidemic in China. Brain, Behavior, and Immunity, 88, $60-65$.

Spitzer, R. L., Kroenke, K., Williams, J. B., \& Löwe, B. (2006). A brief measure for assessing generalized anxiety disorder: The GAD-7. Archieves of Internal Medicine, 166, 1092-1097. doi: https://doi.org/10.1001/archinte.166.10.1092.

Spoorthy, M. S., Pratapa, S. K., \& Mahant, S. (2020). Mental health problems faced by healthcare workers due to the COVID19 pandemic- a review. Asian Journal of Psychiatry, 51, 102119. doi: https://doi.org/10.1016/j.ajp.2020.102119.

Williams, N. (2014). The GAD-7 questionnaire. Occupational Medicine, 64, 224. doi: https://doi.org/org/10.1093/occmed/ kqt161.

Wilson, W., Raj, J. P., Rao, S., Ghiya, M., Nedungalaparambil, N. M., Mundra, H., \& Mathew, R. (2020). Prevalence and predictors of stress, anxiety, and depression among healthcare workers managing COVID-19 pandemic in India: A nationwide observational study. Indian Journal of Psychological Medicine, 42, 353-358. doi: https://oi.org/10.1177/ 0253717620933992.

World Health Organization. (2020). Modes of transmission of virus causing COVID-19: implications for IPC precaution recommendations: scientific brief, 29 March 2020. World Health Organization. https://apps.who.int/iris/handle/10665/ 331616. License: CC BYNC-SA 3.0 IGO.

Xiao, X., Zhu, X., Fu, S., Hu, Y., Li, X., \& Xiao, J. (2020). Psychological impact of healthcare workers in China during COVID19 pneumonia epidemic: A multi-center cross-sectional survey investigation. Journal of Affective Disorders, 274, 405-410. doi: https://doi.org/10.1016\%2Fj.jad.2020.05.081. 
Zhong, B.-L., Luo, W., Li, H.-M., Zhang, Q.-Q., Liu, X.-G., Li, W.-T., \& Li, Y. (2020). Knowledge, attitudes, and practices towards COVID-19 among Chinese residents during the rapid rise period of the COVID-19 outbreak: A quick online crosssectional survey. International Journal of Biological Sciences, 16, 1745-1752.

Zhu, J., Sun, L., Zhang, L., Wang, H., Fan, A., Yang, B., Li, W., \& Xiao, S. (2020). Prevalence and influencing factors of anxiety and depression symptoms in the first-line medical staff fighting against COVID-19 in Gansu. Frontiers in Psychiatry, 11, 386. doi: https://doi.org/10.3389/fpsyt.2020.00386.

Cite this article: Haroon N, Owais SS, Khan AS, Amin J (2020). Prevalence, risk factors and sources of anxiety among Emergency Department healthcare workers in Pakistan during COVID-19 pandemic: A single center survey Experimental Results, 2, e2, 1-13. https://doi.org/10.1017/exp.2020.68 


\section{Peer Reviews}

\section{Reviewing editor: Dr. Xiaoping Wang}

Second Xiangya Hospital, Department of psychiatry, 139 Renmin Middle Road, Changsha, Hunan, China, 410011

This article has been accepted because it is deemed to be scientifically sound, has the correct controls, has appropriate methodology and is statistically valid, and has been sent for additional statistical evaluation and met required revisions.

doi:10.1017/exp.2020.68.pr1

Review 1: Prevalence, risk factors and sources of anxiety among Emergency Department healthcare workers in Pakistan during COVID-19 pandemic: a single center survey

Reviewer: Dr. Ziwei Liu (iD

Hunan Normal University, Medicine, Changsha, China, 410081

Date of review: 21 September 2020

(C) The Author(s), 2020. Published by Cambridge University Press. This is an Open Access article, distributed under the terms of the Creative Commons Attribution licence (http://creativecommons.org/licenses/by/4.0), which permits unrestricted re- use, distribution and reproduction, provided the original article is properly cited.

Conflict of interest statement. none.

Comments to the Author: 1. page 4, line 40. The decimal place of mean and SD should be uniform.

2. All decimal place of $P$ value should be three.

3. page 5, line 4 . The $P$ value cannot be equal and smaller than 0.001 at the same time.

4. page 5 , line 4 . the $95 \% \mathrm{CI}$ contains 1 with the p value smaller than 0.001 . But how is that possible? There must be something wrong. The researchers should check them statistical outcome again.

5. All tables should be three-line tables.

\section{Score Card}

Presentation

3.6

Is the article written in clear and proper English? (30\%)

Is the data presented in the most useful manner? (40\%)

Does the paper cite relevant and related articles appropriately? (30\%)

\section{Context}

Does the title suitably represent the article? (25\%)

Does the abstract correctly embody the content of the article? (25\%)

Does the introduction give appropriate context? (25\%)

Is the objective of the experiment clearly defined? (25\%) 
Analysis

3.4

Does the discussion adequately interpret the results presented? (40\%)

Is the conclusion consistent with the results and discussion? (40\%)

Are the limitations of the experiment as well as the contributions of the experiment clearly outlined? (20\%) 


\section{Review 2: Prevalence, risk factors and sources of anxiety among Emergency Department healthcare workers in Pakistan during COVID-19 pandemic: a single center survey}

Reviewer: Dr. Yumeng Ju

Date of review: 06 December 2020

(C) The Author(s), 2020. This is an Open Access article, distributed under the terms of the Creative Commons Attribution licence (http://creativecommons.org/licenses/by/4.0/), which permits unrestricted re-use, distribution, and reproduction in any medium, provided the original work is properly cited.

Conflict of interest statement. The reviewers reported no Conflict of Interest

Comments to the Author: In this study, the authors sought to investigate the prevalence, risk factors and sources of anxiety among Emergency Department healthcare workers in Pakistan during COVID-19 pandemic. The manuscript is mostly well written. Although there has been a large amount of evidence indicated the anxiety and related risk factors among healthcare workers among other countries, however scarce evidence has been found in Pakistan population.

Specific comments:

Methods:

Is the 109 the number of the total health care workers in ED? Survey sampling and design choice must be led by their purpose. The author attempted to investigate the prevalence of anxiety in ED department in Pakistan. However, the subjects were not randomly sampled among the whole country. Therefore the samples in the current study could not met their purpose.

Page 14 line 25: please specify which confounders you are adjusted for.

In data analysis. How many factors did the authors included in the multivariate regression analysis? In addition, it has been suggested that the number of responders should be 10 times larger that the factors that the regression analysis (or even more).

Results:

Were there any significant differences in the demographics and clinical characteristics reported in Table 1 between the physicians and nurses? It could be recommendable to add p-values of the two groups comparisons and discuss them.

\section{Score Card}

Presentation

3.3

Is the article written in clear and proper English? (30\%)

Is the data presented in the most useful manner? (40\%)

Does the paper cite relevant and related articles appropriately? (30\%)

Context

Does the title suitably represent the article? (25\%)

Does the abstract correctly embody the content of the article? (25\%)

Does the introduction give appropriate context? (25\%)

Is the objective of the experiment clearly defined? (25\%) 
Analysis

Is the conclusion consistent with the results and discussion? (40\%)

Are the limitations of the experiment as well as the contributions of the experiment clearly outlined? (20\%) 